\title{
Management of Innovative Projects as a Mechanism of Development Strategy Realization
}

\section{Tatiana Kashitsyna}

\author{
Ph.D. in Economics, A.P. in Management sub-department \\ Vladimir Branch of Russian University of Cooperation; Email: kashicina@yandex.ru \\ Elena Lovkova
}

Ph.D. in Economics, A.P. in Global Economy sub-department Vladimir Branch of Russian University of Cooperation; Email: nikishinaes@yandex.ru

Margarita Berkovich

Kostroma State Technological University, Kostroma, Russia; Email: ecdepart@kstu.edu.ru

\section{Doi:10.5901/mjss.2015.v6n6s4p186}

\section{Abstract}

In the framework of innovative development of the Russian economy has considerably increased attention to research and innovation. This is due to the state innovation policy of Russia for the period up to 2020. The purpose of this article is the necessity of transition of management of innovation projects Innovation management, refraining from the use of traditional management practices. Effective implementation of this transition requires a number of changes in organizational processes, which leads to a problem related to the compatibility of old and new procedures and structures. Special attention is paid to the identification of specific features of management of innovative projects. The use of various technologies, innovative development and changes. Depending on the nature of innovation - its typology and classification by fields of activity application of various technologies of management of innovative development and changes. The main method in the management of innovation plays technical complexity of the proposed changes and the emotional involvement of the teams in the innovation process. The result of this work is to develop a mechanism for determining the level of innovative projects proposed for state support and the implementation and algorithm of selection of investment and innovation projects. The use of these results will allow for a more objective comparative analysis of scientific and technological achievements aimed at implementing the strategy of development. Innovative approach in the management of innovative projects in the most efficient and sustainable in today's ever-changing world.

Keywords: innovative project, innovative projects management.

\section{Introduction}

The purposes, priorities and tools of the state innovative policy are defined by the strategy of the innovative development of Russia for the period till 2020 which sets long-term parameters of development and reference points of financing of the sector of fundamental and applied science and the support of commercialization of development (The Russian Government, 2011).

Despite the implementation of the innovative model of economic growth, the level of innovative activity remains rather low in the country. Nowadays there are no large-scale technological breaks taking place in the manufacturing industry in Russia, and the outcome of research and development is not being intensively elaborated.

According to the report on the global competitiveness in 2012-2013 presented at the World Economic Forum, the respondents (total number of respondents is 206) expressed different opinions on the scientific research and innovative capacity of Russia. While $51 \%$ of the respondents evaluate it quite highly, $33 \%$ aren't so sure about the opportunity of an effective use of Research and Advanced Development and innovations in Russia. Besides, $42 \%$ of the sampled investors mentioned the necessity of improvements in the Russian entrepreneur culture. The lack of sufficient financing and required infrastructure supporting the starting innovations resulted in the shortage of new projects. This representation is supported by a low rating of Russia in the innovative development and business improvement according to the report (The Global Innovation Index, 2012).

Despite the global problems, the Russian economy in 2012 continued growing, although with a low speed — 
approximately 3,4\% in GDP and about 3\% in the industry. An important positive outcome of the year was the fact that the economic growth was mainly a result of the domestic demand (growth of investments by approximately $7 \%$ and consumption by approximately $6 \%$ ).

In 2012 Russia was in the 51st place (improvement on five positions in comparison with 2011) according to the Global index of innovations appropriated by the European institute of business administration (INSEAD) and the World intellectual property organization (WIPO). Among the BRIC countries Russia superseded Brazil (the 58th place) and India (34th), but goes behind China (34th) (World Economic Forum, 2014). The significant changes that occurred in the recent years as a result of carrying out the Russian innovative policy, have moved the Research and Advanced Development to the foreground of the list of tasks for the government. The respondents' feedback shows that transition to a broader cooperation would allow Russia to discover the new opportunities in innovations and introduction of the new technology. ("Ernst \& Young", 2013)

Due to the world crisis of 2015 and the sanctions imposed against Russian Federation, the economy needs to unleash its industrial, technical, intellectual potential using the innovations. Each region needs to be allocated with a specialization and competitive advantages and to develop in this innovative direction.

The applicability of the research is proved by the necessity of a profound scientific analysis of the innovation development and increasing competitive advantages of the country's regions and products in the global market in general.

Thus, the purpose of this research is to provide a mechanism for defining the level of innovative projects intended for the state support and implementation. The determining factor here is increasing the level of innovation activity in the country and, as a result, - the improvement of the living standards.

\section{Innovative Project and Features of Its Management}

The importance of innovative management approach is obvious with regards to the management of innovative projects as opposed to the traditional management of standard projects. The development of an organization should be defined as a transition from one state to another, which is considered to be more effective for its activity.

The effective implementation of such transition demands introducing a number of changes into the organizational processes - which can cause problems associated with the compatibility of old and new procedures and structures.

The management of innovative projects is one of the high priority courses in modern management science. Unlike a normal production process, each innovative project is unique in its own way, as it addresses to the development of a specific product with certain characteristics and restrictions.

Features of an innovative project:

1. Each innovative project has to pass the "science-production-consumption" cycle. The idea of an innovative project is based on the scientific and marketing researches. Production has to rely on the scientific developments.

2. The increased risks are caused by the complex process of forecasting the results. The introduction of everything new is always connected with high risk of the lack of demand. Depending on the type and nature of innovative researches the probability of positive results is in range from 5 to $95 \%$.

3. Development and implementation of an innovative project. The success at this stage in many respects depends on enthusiasm and personal interest of the staff. A director committed to a high level of creative potential within a company should certainly emphasize any creative achievements of the employees. The researchers' intellectual and emotional abilities are separated; they are self-sufficient, emotionally unstable, light-hearted and in the same time more radical in comparison with administrators. One of the most important elements of a staff management system within an innovative organization is motivation, which is supported by the material incentives only partially.

4. Organization of the workflow for the project team. The project manager is assigned a special status - the innovative project manager. He manages a temporary project team brought together by a single-purpose target or matrix structure. Such structure is created for the promotion of a specific innovation and stops functioning after its implementation.

5. Lack of stereotypes and traditional methods of the innovative project management. Even the most elaborate plan of a project development can significantly change in the course of work.

An innovative project, regardless of its complexity, goes through the certain stages during its "life": from "the project doesn't yet exist", to "the project doesn't exist already" (Dmitriev, J., Filimonova, N., Fraymovich, D., 2014).

When developing a mechanism of the innovative projects management as the innovative management the 
following stages may be followed (fig. 1)

\begin{tabular}{|c|}
\hline Stages of creation and implementation of an innovative project \\
\hline $\begin{array}{l}\text { 1. Preparing a business plan (involves marketing research, preparation of a production } \\
\text { (services) volume plan, preparation of the initial permit documentation, development of } \\
\text { the technical solutions, description of the company management system, labor } \\
\text { management, production costs assessment, risk assessment, assessment of the } \\
\text { commercial effectiveness of the project). }\end{array}$ \\
\hline $\begin{array}{l}\text { 2. Defining the investment opportunities (analysis of the demand for products and } \\
\text { services and the offer of substitute goods subject to the export and import, paid for from } \\
\text { own funds). }\end{array}$ \\
\hline 3. Preparing the documents for a potential investor. \\
\hline 4. Preparing the project documentation. \\
\hline 5. Construction and installation works and clearing for operation. \\
\hline 6. Operating the facility. \\
\hline 7. Monitoring the project implementation. \\
\hline
\end{tabular}

Figure 1. Stages of creation and implementation of an innovative project.

The main groups of processes in the life cycle of an innovative project are as follows:

- initiation of a project,

- planning,

- execution,

- managing,

- finalization.

Considering the life cycle of an innovative project, the role of the project planning stage becomes apparent. It covers practically all fields of knowledge and emphasizes the importance of the communications management at different stages of the project. Another important feature of a project is the areas of the "knowledge" involved in it. According to A Guide to the Project Management Body of Knowledge by the American Institute of project management (PMI PMBoK® Guide), the following areas in this management science can be pointed out:

- integration of the project,

- management of subject domain,

- management of terms,

- management of cost,

- management of works quality,

- risk management,

- management of deliveries (contracts).

Depending on the character of an innovation - its typology and classification by fields of activity - various technologies of innovative development and changes management (fig. 2) may be applicable. The leading role in the innovations management is played by the technical complexity of the planned change and the emotional involvement of the team into the innovative process. 


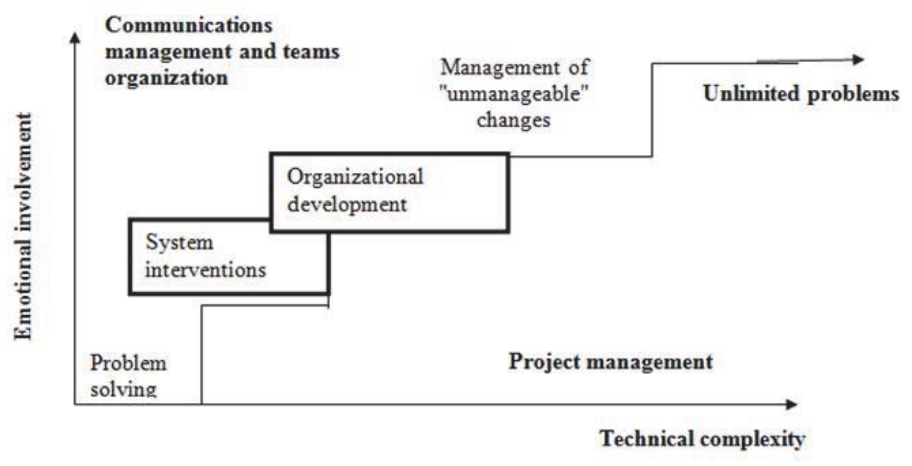

Figure 2. Innovations and management of development and changes

As seen on fig. 2, the following distinctive technologies of the changes management within an innovative project can be pointed out:

Problem solving. This area is associated with the solution of normal routine problems appearing on the daily basis.

System interventions. Management in the situation of an unstable character and a moderate level of the problem's technical complexity, which may as well be considered as a restriction.

Organizational development. Such problems require a longer period for solution and a multi-level approach comprising of a set of the coordinated methods. Innovations are of a structural, organizational nature.

Management of "unmanageable" changes. Such problems are related to the political, religious and economic situations. The solution of such situations is often associated with the change in paradigm and the innovations in the social and economic areas.

Communications management and teams organization. Applies to the situations where human factor plays a large role, and does not appear as particularly difficult in terms of the technical problems solution.

Project Management. This area of the chart is related to the evaluation of the fairly complicated intellectual and technical problems.

\section{Research Methodology}

Considering the innovative project features and the stages of its life cycle, the complexity and uniqueness of the innovative staff's input to each project in particular becomes visible. There is no place for traditional templates and standards, a certain group of executives with certain skills and knowledge is recruited for each innovative project, and a new product with certain restrictions is developed each time.

The general importance of an innovative project may be estimated on the federal, regional, or branch management level within a business entity. The project therefore can be of a federal, regional, or branch importance respectively, or of importance to the business entity. These estimations may be in various combinations in relation to the specific project.

For a regional importance project the major social, budgetary and other issues may be considered as the toppriority problems; the issues in the administratively established directions in science, technology, social and economic development - as a lower-priority; and there are also the on-going issues - such as the regional budget replenishment. For a business entity the importance levels can be more flexible and individual, depending on its position in the domestic and foreign markets, including the assessment of the project's impact on the quality of products and services improvements; expansion and stability of the market sales; costs reduction; social and economic problems solutions; establishing a technological reserve in anticipation of a future breakthrough in the market.

The scale of impact caused by the implementation of innovations directly depend on their expected performance, defined by the following factors: a) material (quality improvement and growth of the product variety); b) technological (productivity growth and improvement in labor conditions); c) functional (growth in management effectiveness); d) social (improvement in the quality of life). Therefore, the economic value (cost) of the innovations for their consumer is directly determined by their expected (predicted) usefulness in terms of overcoming the problem of the utility limitations of all kinds. The cost of innovations for their seller is directly determined by the expected profitability of the sale.

At the present stage of the implementation of innovation in these regions use criteria for selecting projects, such as 
high profitability, low costs and as soon as possible of the project. Undoubtedly, these figures did not meet the criteria for the expected efficacy of the region. Also, in the methods of selection does not affect the dynamics of the project, indicating that the failure to timely correct changes. In the Vladimir region (Law № 90-OZ, 2002) the innovation and investment projects that are underway or completed have been analyzed, the main locations for their implementation are the municipalities with a relatively low official unemployment rate. The analysis revealed that the main indicator of social efficiency is the creation of new jobs.

In some companies social efficiency could not have been achieved due to the lack of manpower in the respective municipalities, caused by the migration to Moscow and the Moscow region. In this regard, such companies have settled the outsourcing contracts to attract additional staff from the CIS countries.

Thus, with the state support of innovation and investment projects in order to create the new jobs and reduce social tension in the labor market the municipalities with a high level of official unemployment require a special attention. In other municipalities the foreign experience may be utilized: establishing the highly skilled job positions, growing the productivity and securing the higher salaries in order to prevent the labor migration.

This research suggests a mechanism for determination of the innovation level (fig. 3) for a project seeking the state support and implementation.

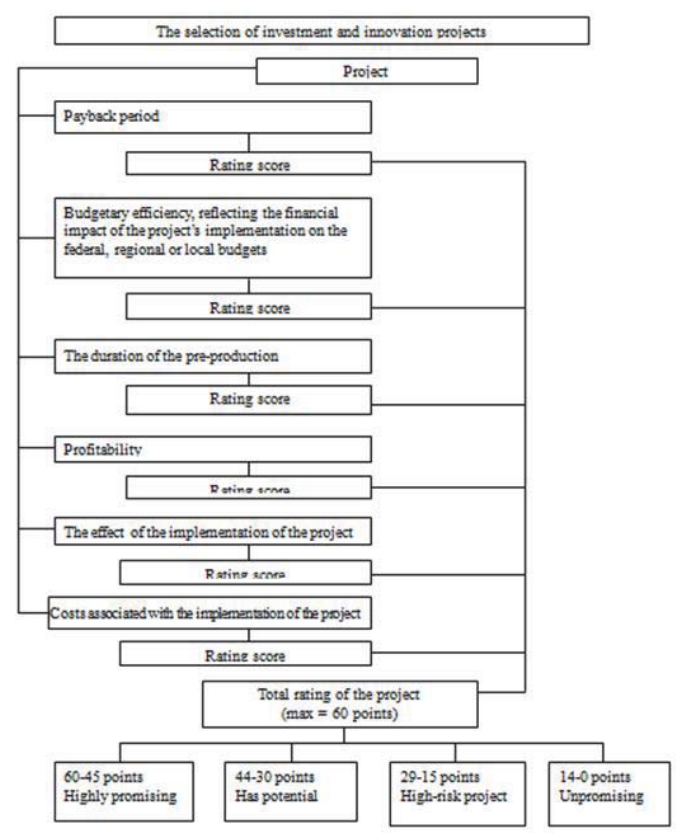

Figure 3. Algorithm for the selection of investment and innovative projects.
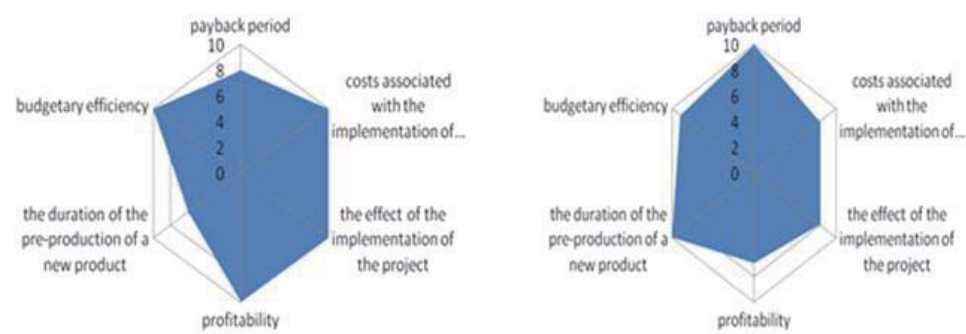

Figure 4. Level of the selection indicators of the innovative and investment project 1 and project 2. 
Plotting an indicators chart for the selection of an innovative project (fig. 4) requires a differentiated approach to the works of a different nature, aimed to define the payback period of the project; the costs associated with the implementation of the project; the effect of the implementation of the project; the profitability; the duration of the pre-production of a new product; and the budgetary efficiency considering the financial impact on the budget on all levels. The indicator fluctuates from 10 to 1 between the highest and the lowest levels of the chart, i.e. the better the value of an indicator - the higher the score.

The scores increase closer to the practical use in the industry. In order to define the general aggregated rank of a project (scientific and technical effect), K. G. Fedorov suggests to multiply the level of originality score and the level of applicability score. It allows to compare projects of a different nature: the fundamental researches with a high level of originality and a low degree of applicability, and applicative projects which can be introduced within a short period of time, but the level of originality is not necessarily high. A low level of one indicator can be compensated by a high level of the other.

Using this method the prospects of a project can be determined, together with its implementation trends and any modifications directed towards achieving the desired results and avoiding the adverse scenarios.

\section{Conclusion}

The main outcome is the conclusion regarding the necessity of the quantitative indicators for the assessment of the efficiency level of the conducted scientific researches. The use of quantitative indicators will allow to carry out the comparative analysis of scientific and technical achievements more objectively.

The main task of the innovation projects management is monitoring the changes in timing. In accordance with the principles of the project management time is the main indicator of the effective implementation of a project.

The most important result of the innovative management of implementing the innovation and investment projects is not the confirmation of variances, but the determination of their scale, the acceptability of such variances in terms of reaching the set targets and identification of the trends of the project's implementation. The acceptability of identified deviations is determined subject to the nature of a project and the scale of the impact of deviations on the fulfillment of the set targets. Therefore, the most important factor of the deviations identified by means of the monitoring is forecasting the consequences of the current situation. In the absence of need for modifications the deviations are considered acceptable, and vice versa.

The management is inseparably linked with unity, coherence of cooperative actions of people in the course of work, which assumes the division of work process between certain workers and the existence of a direct relationship between these persons. The management is based on the production need to coordinate and adjust the activities of a certain people. Management doesn't exist separately as an independent process; it is a part of a general managing system defining its specific features. The specific features of the type of management are defined by the subject of management; in this case that is innovations. Tools, methods and laws of management come out in the operation of the mechanism of management, in the system of collecting, transferring, processing the information etc., but the essence of management is always inseparably linked with the manageable system itself, with its specifics. Therefore the innovative approach to managing the innovative projects is the most efficient and acceptable in the modern constantly changing world.

\section{References}

Dmitriev, J., Filimonova, N., Fraymovich, D. (2014). About optimization of regional investment resources // Life Science Journal. Volume 11, Pages 89-95

"Ernst \& Young". (2013). Research of investment attractiveness of Russia (total number of respondents 206). http://www.ey.com/ Publication/vwLUAssets/Ras2013-rus/\$FILE/Ras2013-rus.pdf

Law № 90-OZ . (2002). On the state support of investment activity by means of the capital investment in the Vladimir Region.

The Global Innovation Index. (2012). Stronger Innovation Linkages for Global Growth, INSEAD and the World Intellectual Property Organization. p. 121, p. 122, p. 123, p. 124, p. 125, p. 126, and p. 127. https://www.globalinnovationindex.org/content/page/GIIHome

The Russian Government. (2011). The strategy of innovative development of the Russian Federation for the period up to 2020. No. 2227$R$

World Economic Forum. (2014). The Global Competitiveness Report 2012-2013. p. 20. http://www.weforum.org/reports/globalcompetitiveness-report-2012-2013. 